\title{
La Revista de Estudios de Administracion Local: sesenta años de existencia
}

\author{
Jaime Rodríguez Arana Muñoz \\ Director del Instituto Nacional de Administración Pública
}

El hecho de que una Revista doctrinal mantenga su presencia ininterrumpida, a lo largo de sesenta años, es sin duda un acontecimiento digno de toda consideración y del que debemos felicitarnos los que desde el pasado y en el presente hemos colaborado a su permanencia, tanto en las responsabilidades de dirección, como en las de autores, colaboradores, personal administrativo, etc.

En el aspecto externo, lo único que ha cambiado con el paso de los años ha sido el título, en el que de alguna forma siempre juegan las mismas palabras: en 1942 Revista de Estudios de la Vida Local, en 1985 Revista de Estudios de la Administración Local y Autonómica y en 2001 Revista de Estudios de Administración Local. Tampoco podemos omitir los cambios en su diseño, que no en el formato y en la periodicidad que de bimestral en sus primeros pasos, pasó a trimestral en 1968 y a cuatrimestral desde 1990.

Los cambios introducidos en el título de la Revista se justifican por la adaptación a la realidad política y jurídica producida por la organización territorial del Estado, que discurrió de un modelo centralista a otro descentralizado y que en su momento, 1985, trató de cubrir el ámbito doctrinal autonómico aún poco cultivado, reuniendo en una sola revista científica los niveles autonómicos y locales. Aquella experiencia positiva hace quince años, dejó de serlo cuando aparecieron diversas publicaciones rigurosas en diversas Comunidades Autónomas, que estaban consolidando y han conseguido disponer de un estimable corpus doctrinal de Derecho autonómico.

Pero junto a ese factor, ha surgido también una corriente muy importante de fortalecimiento del Municipio como verdadero poder del Estado, lo que ha supuesto la suscripción del Pacto Local, acuerdo de trascendencia aún no cerrado, pues mientras que el Gobierno de la Nación ha llevado a la legislación general aspectos de primera magnitud, como la defensa de la autonomía local ante el Tribunal Constitucional, se está recorriendo el camino de los sucesivos acuerdos entre las respectivas Comunidades Autónomas y las Entidades locales de su territorio, para 
completar la articulación competencial y de recursos entre todas las administraciones territoriales.

El rigor y calidad de una publicación científica sólida también se caracteriza por el número y condición de sus directores, en este caso catedráticos de Derecho Administrativo los cuatro, cifra muy corta para seis décadas de ejecutoria, pero que hablan de su alta condición intelectual y personal. El primero fue don José Gascón y Marín, exministro de Educación de la monarquía alfonsina, catedrático de la Universidad de Madrid y maestro de administrativistas de la primera mitad del siglo XX. El testigo de su larga ejecutoria fue recogido por el profesor José María Boquera Oliver, catedrático de las Universidades de Valladolid y Valencia, y más adelante por el profesor Francisco Sosa Wagner, catedrático de la Universidad de León. En los años siguientes, avanzado el período de consolidación y normalización democrática, la dirección fue asumida por el catedrático de la Universidad de las Islas Baleares, profesor Avelino Blasco Esteve, quien la ostenta en la actualidad.

La Revista de Estudios de Administración Local, que hoy estrena título, no es una nueva experiencia editorial, es la continuidad de la misma publicación que desde 1942, bajo distintas rúbricas y diseño externo, que no formato, ha concurrido a su cita periódica con Municipios y Diputaciones, electos y funcionarios locales desde hace sesenta años, por lo que ha mantenido la numeración correlativa desde el primer número en 1942, correspondiendo al presente el 285 . Lo más meritorio ha sido que no perdió en ningún momento el carácter doctrinal, razón que motivó su creación y si hasta 1968 contenía información de actividades del antiguo Instituto de Estudios de Administración Local, ésta fue traspasada en aquella época a otras publicaciones divulgativas, por lo que ganó en rigor y especialización.

Ha sido y es una Revista que ha tratado con rigor, a lo largo de su existencia y desde una perspectiva jurídico-científica, los problemas de la Administración local española, fuese cual fuese el momento político o legal por el que transitase. Pues incluso en números cuya referencia a estos marcos era obligado, como la tramitación y aprobación de los sucesivos proyectos de ley de régimen local desde 1945 a 1985, siempre se hizo con la suficiente imparcialidad para derivar hacia planteamientos técnicos, recordemos a estos efectos las indicaciones sobre la ausencia del concepto autonomía local en dicho proyecto, señalado por don Luis Jordana de Pozas y la defensa realizada por el entonces director del IEAL, profesor Ruiz del Castillo, argumentando que el concepto se encontraba implícito en todo el texto legal. 
Los límites impuestos por la situación política era evidente que afectaban a la libertad de opinión y tampoco podía realizarse una crítica a la ordenación política del régimen, sin embargo, existieron posturas que en otro medio no hubiesen sido toleradas, probablemente por tratarse de una publicación doctrinal de difusión limitada al mundo local, aunque por aquellos tiempos la Revista tenía más de dos mil suscriptores, el caso es que surgieron importantes controversias, siempre en un marco estrictamente doctrinal y científico.

Recordemos a estos efectos, que en el número 68 de la Revista, correspondiente a los meses de marzo y abril de 1953, el profesor García de Enterria, que por aquellos años comenzaba su carrera de brillante jurista, en un artículo titulado "La primera derogación importante de la Ley de Régimen local", se refería a la primera e inadvertida derogación importante experimentada por dicha norma, pues la promulgación del texto refundido de la Ley de lo Contencioso-Administrativo de 8 de febrero de 1952, afectaba a la Ley de Régimen local en cuestión de tanta importancia como la regulación del recurso contencioso-administrativo. En el mismo sentido, señalaba el profesor García de Enterría, el artículo 375 del Reglamento de Organización, Funcionamiento y Régimen Jurídico de las Corporaciones locales de 17 de mayo de 1952, aprobado tres meses después de la mencionada Ley, planteaba dudas sobre la legalidad del Reglamento en cuestión, pues transformaba la Ley de lo ContenciosoAdministrativo en supletoria.

A este ejemplo seguirían otros de análogo rigor, por lo que esta Revista debe considerarse como una fuente indispensable para el conocimiento de la evolución del Régimen local español de los últimos sesenta años, con el valor añadido, al margen de la dinámica introducida por los cambios políticos hacia un sistema de libertades públicas, por las transformaciones derivadas de dicha dinámica desde un modelo de Estado centralista a otro descentralizado.

Y ésta fue la oportuna causa que aconsejó integrar en un momento de cuasi vacío doctrinal, como decíamos anteriormente, el componente autonómico al local, lo que afectó no sólo al título de la Revista sino a su contenido, aunque siempre sin olvidar y sin que sufriera detrimento el horizonte municipal, cuestión prioritaria en el marco competencial del propio organismo encargado, como es sabido, de la selección y formación de los funcionarios de los Cuerpos Nacionales de la Administración local.

Un experimentado camino se abre en esta nueva etapa de la Revista, cuya especialización se ciñe exclusivamente al universo local, aunque es obvio que en un Estado de las Autonomías no se puede prescindir de estu- 
diar los problemas de encaje y articulación de los Municipios con las Comunidades Autónomas, cuestión que no será ignorada en esta nueva etapa, pero siempre desde la perspectiva local.

La Revista mantendrá su tradicional sección de Doctrina, pero es deseo de la Dirección y del Consejo de Redacción de la misma introducir una adición en la sección II que se denominará Experiencias y Crónicas, al objeto de dar entrada a las posibles colaboraciones empíricas que funcionarios y electos locales puedan aportar para enriquecer el conocimiento de la Administración local. Respecto a las secciones de Jurisprudencia y Recensiones se mantendrá su contenido en los mismos términos que hasta ahora.

Por las anteriores razones es oportuno realizar un llamamiento a Alcaldes, Concejales, Diputados, Funcionarios de Habilitación Nacional y a todos los Funcionarios de los Ayuntamientos y Diputaciones, para que no sólo utilicen esta Revista como instrumento de estudio y trabajo, sino que hagan llegar sus colaboraciones, tanto doctrinales como experiencias o crónicas, para enriquecer su contenido, pues resulta indudable que, con la colaboración y aportaciones de todos, conseguiremos una gran publicación y mantendremos el prestigio adquirido a lo largo de los sesenta años anteriores.

Para cumplir este objetivo, se cuenta además con la inestimable participación de un Consejo de Redacción dotado del más alto nivel científico e intelectual, con un componente pluridisciplinar, que garantiza el rigor y la seriedad de la Revista, con la existencia de un valor añadido como es la persona de su Director el profesor Avelino Blasco Esteve, cuyas cualidades son de sobra conocidas. Desde estas líneas quiero hacerles llegar a todos mi felicitación más sincera por sus esfuerzos y el ruego de que persistan en su trabajo, incluyendo a todas las personas que de alguna manera participan en los diversos procesos de elaboración de la Revista, especialmente a doña Elisa Romero Sebastián que desde hace años desempeña las funciones administrativas de la misma.

Finalmente, indicar que con el último número de REALA se ha producido un cambio en la Secretaría del Consejo de Redacción, cuya titular doña Isabel Benzo Sainz ha sido designada alto cargo del Ministerio de Administraciones Públicas, pasando a integrar el Consejo de redacción de la Revista de Estudios Autonómicos, sustituyéndola don Enrique Orduña Rebollo, director de la Biblioteca del INAP, persona de acreditado prestigio entre los estudiosos de la Administración local, tanto por sus publicaciones, como por su trayectoria desde el antiguo Instituto de Estudios de Administración Local. 


\section{Doctrina}


